\title{
Defining poverty as distinctively human
}

\author{
H P P Lötter \\ Department of Philosophy \\ University of Johannesburg
}

\begin{abstract}
While it is relatively easy for most people to identify human beings suffering from poverty, it is rather more difficult to come to a proper understanding of poverty. In this article the author wants to deepen our understanding of poverty by interpreting the conventional definitions of poverty in a new light. The article starts with a defence of a claim that poverty is a concept uniquely applicable to humans. It then present a critical discussion of the distinction between absolute and relative poverty and it is then argued that a revision of this distinction can provide general standards applicable to humans everywhere.
\end{abstract}

\section{INTRODUCTION}

Poverty is arguably the biggest problem facing humans today. In 1995 it was said that more than one billion people "live in abject poverty, most of whom go hungry every day" (Copenhagen Declaration 1995:6). Poverty is the greatest cause of suffering on earth and responsible for more preventable deaths than anything else (Gordon 2002:74). We, human beings on earth, have all the knowledge and resources we need to eradicate poverty everywhere (UNDP 1997:iii). Never before has poverty been so high on the agenda of so many governments and international bodies. The world has never before witnessed so many of heads of state and government publicly commit themselves to eradicate poverty. 117 heads of state or government attended the World Summit for Social Development in 1995. At that event the "largest gathering yet of world leaders pledged to make the conquest of poverty, the goal of full employment and the fostering of stable, safe, and just societies their overriding objectives" (Copenhagen Declaration 1995:vii). Despite all this, poverty still persists as a massive problem affecting hundreds of millions of human beings across the globe.

Most of us can easily identify human beings suffering from poverty, but find it slightly more difficult to understand poverty properly. In this essay I attempt to deepen our understanding of poverty by interpreting the conventional definitions of poverty in a new light. I argue for the general claim 


\section{Defining poverty as distinctively human}

that poverty is a concept uniquely applied to a specific human condition. To establish this claim, I present the following arguments:

- I first point out that the concept of poverty is applied exclusively to human beings in everyday language.

- Next I show that the concept of poverty has a distinctive evaluative dimension that depicts this human condition as an undesirable or negative state of affairs for humans to be in.

- The third argument first refines the well-known distinction in the human sciences between absolute and relative poverty. I then demonstrate that the notion of absolute poverty is in need of the definition of relative poverty so as to indicate clearly that poverty implies a loss of a person's humanity.

Perhaps some readers want to object at the starting point, arguing that middle class academic researchers should not define and identify a condition they have no experience or intimate knowledge of. They should rather allow poor people to voice their own definition of a condition they suffer publicly and often embarrassingly so. Such an objection contains controversial assumptions. One assumption borders on solipsism that suggests that one "has to be one to know one." Another assumption is that people experiencing a particular condition necessarily have the ability to best describe that condition accurately and insightfully. Both these assumptions would invalidate large parts of the work of the human sciences.

Attempts at a "bottoms up" definition of poverty by academics can work if done in the following way. In the process of constructing such definitions, researchers deliberately select people with special characteristics, i.e. those who have experienced severe poverty. Researchers also sometimes consult social workers or aid workers thoroughly familiar with more serious cases of poverty as informants. Thus, researchers make use of reports by those with insider knowledge of poverty, or depictions by professionals with intimate expert knowledge of humans living in poverty.

Researchers then interpret the experiences reported and construct a definition from them, transposing poor people's self-descriptions into the typical theoretical constructs employed in the human sciences. Thus, in practice this kind of definition rests on the idea that a definition of poverty must be developed in dialogue between the discourses of the human sciences 
and the self reported experiences of those who are poor, or who are in close contact with poor people.

In this way our academic understanding of concepts are developed in dialogue with people affected by poverty. The contents of the definition of poverty can thus cohere with people's everyday experiences of the phenomena the researchers wish to portray. Furthermore, theoretical definitions of concepts like poverty must be tested for the illuminating value they have in clarifying the nature of poor people's experiences.

\section{POVERTY AS UNIQUELY HUMAN IN EVERYDAY LANGUAGE}

In recent UN Development Reports $(1997,2000)$, the authors use the term "human poverty". Why add the adjective "human" to the concept of poverty? Is it possible that other living beings like plants and animals can also suffer from, or live in, poverty? Do we speak of "animal poverty" or "plants suffering poverty" in everyday language? Let us test this proposal by means of an example. Imagine an elephant in a small zoo. The zoo has inadequate financial resources. The elephant is cramped in a smallish cage with no trees, shrubs, or grass. No other elephants are in sight. For more than three years the elephant has not had enough food and water. As a result the animal is in a bad physical condition, easily susceptible to disease and has many sores on its body. The elephant also seems psychologically depressed, communicating its negative emotional state by means of enfeebled body language and mournful sounds.

Anyone seeing the elephant in this state realizes that it might soon die. The condition and circumstances of the elephant roughly correspond with those of a human being suffering from severe poverty. The elephant might be judged to be suffering from neglect and cruelty, but would we describe the elephant as poor, or suffering from poverty? The concepts poor and poverty are not usually applied in this way when talking of an animal, except when we exclaim in a pitiful voice, "Oh, poor elephant!" In this case we use "poor" metaphorically to express the bad condition and pitiful state of the animal.

In contrast to our description of the elephant, in the case of a human being without the minimum necessaries to sustain physical health we describe the person as suffering from absolute poverty. This implies that human beings in whichever part of the world are judged poor if they do not have adequate economic capacities to ensure access to food, shelter, clothing, security, and medical care needed to maintain their physical health. Why then do we distinguish in this way, calling humans poor but not elephants? 


\section{Defining poverty as distinctively human}

One might suggest the crucial difference is the relationships the elephant and human have to other human beings. The elephant is being enslaved and imprisoned in a cage by a member of a more powerful species that is not taking proper care of the animal. The human does not have such a relationship of enslavement or imprisonment with other humans and thus could be described as free to autonomously determine his or her own life.

However, the example might be misleading if read in this way. Suppose we find this elephant in a similar emaciated condition where it roams freely, without restrictions imposed by humans, on the African savannah during a massive drought. Again, I am sure we will not describe the elephant as living in poverty, or suffering from it. We might say the elephant suffers as a result of drought, or that the elephant is a victim of a natural disaster. When we exclaim, "Poor creature!" we are not describing its situation in terms of poverty, but using the word "poor" metaphorically to express our compassion with its suffering.

Thus, in our everyday use of language poverty is a concept uniquely applied to humans. If this is true, does the concept of poverty express something particularly important about what it means to be human?

\section{POVERTY AS EVALUATIVE CONCEPT}

Perhaps another feature of the concept of poverty can get us closer to unravel the meaning of poverty as concept uniquely applied to humans. Poverty is not only used as a descriptive concept, that is to describe a certain human condition, but also in a prescriptive way to comment on, or evaluate, human lives. Pete Alcock (1993:6) defends the view that the concept of poverty also contains an implicit imperative to act to relieve or eradicate someone's poverty, besides its descriptive function. Jo Roll claims $(1992: 7,8)$ that poverty denotes "a kind of avoidable suffering" that implies onlookers "cannot just stand by and watch; they must take action." I suspect Alcock and Roll are onto something important, but overstate their point. If they are correct that the concept of poverty implies that non-poor people must do something about the effects of poverty on people, the world would perhaps have had less poor people on all continents. Would people not have heeded the implicit call to action in the word they use to describe the misery and hardship of so many fellow human beings?

Alcock and Roll may be correct, though, if we weaken their claim to that of saying that the concept of poverty has an evaluative component. Perhaps the judgement by Gordon, Pantazis and Townsend (2000:91), that poverty is not only a scientific concept, but also a "moral concept" is closer to the truth. Srinivasan's (1994:241), remark that "Hardly anyone would choose to be 
poor" neatly illustrates this evaluative component in the concept of poverty that is that poverty is an undesirable and negative state of affairs few people would choose out of their own volition.

The claim that the concept of poverty has an evaluative aspect can be unpacked and defended as follows. When describing a human being as living in poverty, we normatively evaluate that person's life and judge it to be unworthy of how humans ought to live. To live in poverty, or to suffer poverty, exposes the victim to a lifestyle judged to be below the minimum standard appropriate to humans. Thus, to describe someone as poor is the result of a normative judgment that a specific human being has inadequate economic capacities available to live a life that conforms to the minimum standards a group of humans have implicitly agreed upon as minimally adequate for themselves. This idea squares better with one of Alcock's remarks (1993:9) that people living in poverty "by definition" find themselves in "an undesirable or negative situation (unacceptable state of affairs)."

Let us test this idea by means of an example. Suppose Smith is an environmental activist. He wants to stage a personal protest against the consumerist lifestyle in First World countries that he thinks is responsible for the consumption of energy resources that causes global warming. Instead of building a house like everyone else, he digs an underground chamber for his family to live in, without using any conventional building materials or household appliances. The soil in his chosen location is stable enough not to pose any threat of collapsing. He decorates the interior with natural materials that he removes from nature without doing any visible harm. Smith does not use any source of energy that contributes to an increase in greenhouse gases. He thus relies on a few simple candles for lighting and chooses devices for cooking that utilize solar power. No indoor heating is needed, as the temperature below ground is stable at normal room temperature. The family cultivates most of their food in a small garden and they own only a few items of necessary clothing. Through this lifestyle they want to demonstrate to others how small the ecological footprint of a human family can be.

The family's standards of personal hygiene are lower than the rest of society due to their minimal use of water, consumer products and household appliances. Their clothing appears rather dirty and neglected for similar reasons. Their physical health is good, as their garden produces an adequate supply of nutritious food. Smith earns a lot of money in his job as accountant, which he mostly donates to environmental activist groups. Smith and his family are judged by their community as weird and wacky. They are shunned by many as a result of their appearance, hygiene, and unconventional 


\section{Defining poverty as distinctively human}

lifestyle. They do not have any close friends whom they entertain in their underground chamber.

Are Smith and his family poor? We could hardly call them poor if they have chosen this lifestyle and have enough economic capacities to live a perfectly "normal" life. Although the family cannot be called poor, they do violate our sense of what constitutes "normal human living" in current society. They do not comply with the standards of living judged to be appropriate for humans in our society. In contrast, if McArthur were to follow exactly the same lifestyle as Smith with the exception that both she and her partner are unemployed with no income, their family would surely be described as poor. McArthur and her family simply do not have the economic capacities to choose any other lifestyle. Jenkins is a different case, though. Jenkins lives exactly as Smith does, or more accurately, 5,000 years ago he lived exactly as Smith does now. Jenkins, one of the leaders in his tribe, was very proud of his underground chamber with separate rooms for every family member. His enormous physical strength and endurance enabled him to build a house underground envied by others in the village. His use of beautiful stones collected from the top of the mountain and tree trunks dragged from the dangerous forest was regarded as innovative decorations.

Although long ago Jenkins lived exactly the same life as McArthur now, Jenkins cannot be judged to have been poor. McArthur, though, is poor. In terms of his society's standards of what constitutes an appropriate lifestyle for human beings, Jenkins excelled. The society in which McArthur lives gives a different, more demanding, content to the standards of what constitutes a minimally acceptable, appropriate lifestyle for human beings. McArthur fails to live up to these more demanding standards due to her poverty, her lack of economic capacities. Smith, though, is a different case. He rejects these societal standards as inappropriate to adopt as lifestyle for so many humans on a fragile planet with limited resources. Smith is not poor, as he has freely chosen to live according to different standards. Despite having more than enough economic capacities to fulfil societal requirements, his project is to challenge the standards his society uses to determine poverty levels. By doing this, he wants to lower consumption patterns in favour of safeguarding the earth's fragile resources.

The example can be explored further to bring out the idea that every society has standards for what is regarded as suitable styles of human living made possible through the use of economic capacities and exchange of resources. Suppose Thompson is too poor to afford accommodation. The best he can do is to sleep in an old dilapidated pigsty at the farm where he works. $\mathrm{He}$ has nowhere to hang his clothes, no bathroom or kitchen, and feels too 
embarrassed to invite any friends or family to visit. In most human societies his "home" would be considered unfit for human habitation. Imagine Thompson explores the farm and finds a cave used by thousands of bats. He decides the cave provides better accommodation, as it is bigger and has more privacy from prying human eyes. He meets an old acquaintance, Thomas, in town and blurts out that he lives in a cave. Thomas is unfamiliar with Thompson's present circumstances, but remembers Thompson as an adventurer from school days. Thomas eagerly wants to visit the cave, while Thompson is too embarrassed to stop him. At the cave Thomas learns that Thompson is not an exploring researcher observing fascinating animal behaviour, but someone too poor to afford better living conditions. Will Thomas still be excited about Thompson's chosen abode/dwelling? Having taken in the full situation, will Thomas reckon that his old acquaintance, or any human being for that matter, should live like that?

What is appropriate accommodation for humans at a particular time and place? To judge that involves the following. The kind of shelter fit for human use depends on the materials, skills, and technologies available to people in a society, combined with the climate and the particular purposes for which they use housing. Almost all other living beings can be 'left outside' to find shelter for themselves if they wish, but we judge members of our species differently. We expect fellow humans to have access to housing adequate enough to shelter them against the elements, to provide adequate space for everyone living there, to serve as workshop for household activities, and provide privacy for those activities judged to be of concern to individual household members only.

Obviously the exact ways different societies have set their standards have varied enormously through history and culture. But nevertheless, it seems as if every society has some kind of determinate standards for appropriate accommodation. Igloos, tents, huts, caves, paper-houses, mansions, flats - whatever materials, technologies, skills, or functional ideas were combined, the use of these things were judged to provide the kind of shelter needed by members of our species in the particular circumstances of a specific society. Human beings without the defined minimum standard would have been assisted to find something appropriate, unless they were considered to be outside the human community. Those humans who are ostracized or marginalized for whatever reason - as poor people often are are left to their own devices.

\section{ABSOLUTE AND RELATIVE POVERTY}

I have thus far argued that (1) the concept of poverty is only applied to humans in everyday language and (2) poverty is an evaluative concept used 


\section{Defining poverty as distinctively human}

by human societies to set minimum standards for those aspects of human lifestyles acquirable through economic capacities. Such lifestyles are judged appropriate for human beings, or not, in the context of the society's available knowledge, ideas, resources, and circumstances. Every society has standards for human lifestyles that determine whether a lifestyle is considered worthy of human beings or not. If a human being cannot acquire a worthy lifestyle due to lack of adequate economic capacities, we judge that person to be poor.

What is the link between this definition of poverty as distinctively human and the traditional distinction human scientists make between absolute and relative poverty? How have social scientists used the concepts of absolute and relative poverty? Can the use of these concepts be improved by the argument that the concept of poverty signals a standard of living that is below what is judged to be appropriately human in a specific society? In the next section I will argue for revised definitions of the concepts of absolute and relative poverty, based on the idea that it is significant that we apply the concept poverty only to a certain condition suffered by humans. I will show that the concept of absolute poverty portrays a particularly severe condition suffered by humans. I will also argue that the concept of relative poverty illustrates why poverty is a condition that violates the worth and dignity of human beings as understood in a particular society.

\section{ABSOLUTE POVERTY}

In his groundbreaking research, B Seebohm Rowntree (1901) gave a definition of poverty that went unchallenged for almost half a century. This definition requires critical scrutiny, as slightly modified versions persist in contemporary use of the idea of absolute poverty. After discussing the most influential definitions, I will defend a revised definition of absolute poverty.

Rowntree takes families as unit of investigation. He defines families as poor if their income, total earnings, or "minimum necessary expenditure" cannot obtain or provide "the minimum necessaries for the maintenance of merely physical efficiency" for a family of their size (Rowntree 1901:viii, 87). He explains this idea as "the minimum of food, clothing, and shelter needful for the maintenance of mere physical health" (Rowntree 1901:87).

The income needed for the minimum necessaries will vary with both the size of a family, as well as with the food required "by the severity of their work" (Rowntree 1901:97). Acknowledging these variations, Rowntree investigates which kinds of foods and how much thereof would be adequate to maintain physical health (Rowntree 1901:viii). He also notes what workers would have to pay for these foods (Rowntree 1901:103). Thus, what might initially have seemed to be an inflexible universal standard applicable to every 
family in an identical way, Rowntree adapts to a standard tailored to the size of the families and the markets they have access to.

Rowntree's slight softening of the application of his austere minimum standard for determining poverty is undone by some of his other assumptions. He applies the standard on the strong assumption that poor families have good knowledge of the most nutritious foods and where to buy at the best prices. He makes this assumption to guide his research despite the fact that he knew they did not have that kind of knowledge (Rowntree 1901:105). He furthermore assumed that poor families used all their available earnings for purposes of maintaining "merely physical efficiency" (Rowntree 1901:viii). If people had adequate income to afford the minimum necessaries for maintenance of physical health, but could not do so as a result of using part of their available income for other purposes, Rowntree described them as suffering from secondary poverty (Rowntree 1901: viii). These people are poor because part of their earnings was "absorbed by other expenditure, either useful or wasteful” (Rowntree 1901 :viii).

Rowntree defines primary poverty as a condition that occurs when a family's full income, combined with sophisticated consumer skills, cannot enable them to provide for a family of their size and with their levels of activity the minimum food, shelter, and clothing to be physically healthy. The strength of this definition is the provision of a threshold below which poor people's bodies will begin to suffer ill health of some or other kind. Despite the flaws in his attempted expert judgement to work out the details of an adequate diet and the over-optimistic assumptions about the skills and knowledge of poor consumers, Rowntree's definition provides a basis for the idea of absolute poverty that is generally accepted today. It might be difficult to spell out the exact nutritional requirements for each person with their bodily activities and to determine the cost of such an adequate diet in different localities, regions, countries, and continents (Streeter 1994:234). Nevertheless, it stands to reason that people without adequate food, shelter, and clothing will suffer some or other form of bodily harm, even if only loss of weight and increased susceptibility to disease.

Rowntree's definition lives on in modified and adapted versions that now define absolute poverty. All these versions assume that human beings require similar things to maintain their physical health, such as a basic minimum of nutritious food, shelter to protect against the elements, proper clothing for diverse climatic conditions, security, and medical care. Although the nature and cost of these provisions differ from society to society, a baseline applicable to all humans can be set: a person is absolutely poor if you do not have sufficient economic capacities to ward off a decline in 


\section{Defining poverty as distinctively human}

physical health. The decline can be determined through various measuring instruments: loss of weight due to lack of enough food, weight gain as result of lack of resources to procure food providing adequate nutrition, increased susceptibility to disease, et cetera (Tarp et al 2002).

Note the use of the concept economic capacities instead of economic resources. Rowntree assumed that poor people would be streetwise consumers able to buy valuable products in the most economical way, knowing that few of them can in fact do so. He never examined or studied the abilities of poor people to deal with resources wisely, or not. Although his assumption is too stringent a requirement to expect most consumers to fulfil, let alone only the poor ones, Rowntree's assumption touches on an important issue. He did not take sufficient account of the fact that different people usually do not display the same skills in using economic resources. To acknowledge this variable human characteristic thus makes the concept economic capacities far more acceptable for use in a definition of poverty than the notion of only economic resources. Amartya Sen (1984) alerted us to the importance of our "conversion capacity," that is, our capacities to utilize resources efficiently or not. Sen's convincing argument about this issue thus makes the use of the idea of economic capacities to refer both to resources as well the ability to utilize resources "to provide adequately for themselves" (Alcock 1993:61) more attractive. Using capacities instead of resources can avoid embodying an assumption in the definition of absolute poverty that ordinary consumers possess skills of smart economizing on scarce and valuable resources. If we include capacities in the definition of poverty we can make reasonable allowance for the small failings and non-malicious wastage that ordinary people frequently incur in their daily consumer activities.

In his classical study of pauperism, Charles Booth (1892) exemplifies the kind of generous and humane attitude toward poor people that I want to endorse in the process of determining the absolute poverty line. Note how he identifies with the very human shortcomings and failings of poor people whom he has studied:

... they, like all of us, are nothing much to boast of morally, and are far from wise. They quarrel with their bread and butter; they throw away their chances; they spend when they should save; they most of them drink, and many of them get drunk; they marry imprudently; they spoil their children; they buy finery; they borrow money and lend it; they trust their lodgers, and commit inconceivable follies of many kinds.

(Booth 1892:45) 
Booth assumes that in these matters poor people are "like all of us." We all have such human failings in our consumer behaviour. Many non-poor people waste resources and do stupid things with their money, but they are shielded from slipping into poverty by their adequate share of economic resources. If their share of economic resources were close to the poverty line, they would have been poor as well.

Not all contemporary definitions of absolute poverty are sufficiently precise. Take, for example, the definition adopted in The Copenhagen Declaration and Programme of Action (1995:57). Absolute poverty is formulated as "a condition characterized by severe deprivation of basic human needs, including food, safe drinking water, sanitation facilities, health, shelter, education and information. It depends not only on income but also on access to social services." Although many people have an intuitive understanding of what the definition wants to convey, it is difficult to figure out what exactly "severe deprivation of basic human needs" means or to determine when precisely someone reaches that point. To operationalize this idea with the aim of developing a measurable baseline or poverty line can be very difficult, even granted that any attempt at ranking people in this way "will always contain a measurement error and, if a poverty line is used, there will always be a number of misclassified individuals" (Halleröd 2000:171). The definition used by the World Bank is hardly more precise. This definition says that poverty is "the inability to attain a minimal standard of living, interpreted to include not only consumption of food, clothing, and shelter, but also access to education, health services, clean water, and so on" (Squire 1993:377; World Bank 1990:26). What exactly does "minimal standard of living," in the World Bank definition mentioned above, imply for each of the categories mentioned, when applied to specific societies? The meaning is not clear at all.

I want to claim that the alternative definition of absolute poverty I propose is more precise and better able to be operationalized into a baseline. We can measure gradual deterioration of physical health in human beings in various ways through different measuring instruments by studying things such as intake of nutritious foods, weight loss, stunted growth, etc.

Alcock (1993:58) raises an objection to a definition of absolute poverty that implies a sufferer "does not have enough to live on." He judges this formulation "a contradiction in terms" and asks the rhetorical question: "... how do those without enough to live on, live?" Alcock exploits an imprecise formulation about serious human misery. His rhetorical question fades if confronted with my more precise definition given above. Thus, people without adequate food, clothing, shelter, security, and medical care suffer at least a gradual, if not sudden, decline in physical health. People living in absolute 


\section{Defining poverty as distinctively human}

poverty can stay alive for a long time whilst their physical condition and health continue to deteriorate. At some point their living in absolute poverty meshes into destitution, a condition characterized by extreme hardship and miserable desperation (see Dasgupta 1992). Scenes of emaciated human beings barely alive in their destitution are common in some parts of the world. To see human beings in this condition usually shock and overwhelm human observers.

Although the definition of absolute poverty provides a universally applicable baseline of poverty, I want to claim that using only this baseline as measure of poverty strips human beings of their humanity (see Jones 1990). This baseline implicitly assumes that poor people just above it, with economic capacities that just enable them to maintain physical health, are living lives compatible with their status as human beings. Is it a life befitting the status of human beings to be only able to avoid a deterioration of physical health, but not to be able to engage in social activities? The baseline implies that as humans these people need not be participants in the social life of a community, need no educational empowerment, requires no recreational entertainment, nor do they have any personal or communal events to celebrate with others. To live a life excluded from generally accepted social activities that normal human communities engage in is to live a subhuman life, i.e. a life in which core activities typical of the human species are impossible to do. In addition to the misery of struggling with insufficient economic capacities, people just above the absolute poverty line suffer the humiliation of being incapable of living lives judged as fulfilling their society's minimal requirements to qualify as human.

\section{RELATIVE POVERTY}

The shortcomings in Rowntree's definition identified above lead us to the alternative and wider definition of poverty. How? One shortcoming of Rowntree's definition emerges from the following question. Can we really judge people as "not poor" if they only have the minimum food, clothing, and shelter to protect their physical health? If all the family's earnings can just cover their expenses for these minimum necessaries, they still have no transport, they cannot buy gifts for special occasions like birthdays and Christmas, have no access to any entertainment that cost money, cannot invite friends for tea or dinner, and so on. Furthermore, they are required to show much self-discipline in their consumption so as never to buy newspapers, magazines, sweets, or anything else that does not secure physical health. They cannot entertain friends, go to shows, or be spectators at sports events. To have one's freedoms curtailed in such a way and to 
display such frugality can be very demanding. Not able to participate in normal social activities and practices of one's society means Rowntree's non-poor people become excluded as participants in the generally accepted activities of a normal society. Peter Townsend $(1954,1979)$ formulated these objections and the major alternative definition of poverty to address the shortcomings of Rowntree's definition.

Thus far I have argued that the strict absolutist definitions of poverty with their exclusive focus on the minimum requirements for mere physical survival and maintenance of physical health can be perceived as inhuman if presented as the only definition of poverty. The absolute definition is useful for setting a baseline for a particularly severe kind of poverty, but needs to be supplemented by a second kind of definition. There is surely more to human life than mere physical survival and health? For this reason I will next explore the wider definition of poverty proposed by human scientists who classify people as poor if they cannot participate in the social activities of their community. This definition of relative poverty clearly shows why being poor is inhuman and thus why the concept of poverty functions to indicate a specific kind of loss to a person's human dignity.

In response to Rowntree's influential research, Townsend $(1954,1979)$ formulates an alternative, wider definition of poverty. He develops his definition as response to Rowntree's definition. Townsend (1954:132) judges the standards set by Rowntree as not related well enough to the "budgets and customs of life of working people." He also disagrees with the austere ways in which Rowntree proposed poor people ought to have spent their money. Townsend (1954:133) accuses researchers like Rowntree of expecting poor people to act "like skilled dieticians with marked tendencies towards puritanism" in their choice of food products. To spend their money according to such expectations, poor people would need "virtues of self-denial, skill and knowledge not possessed by any other class of society" (Townsend 1954:133). Townsend therefore formulates a broader definition of poverty. His definition of relative poverty takes as starting point the idea that poverty must be understood relative to "the accepted modes of behaviour in the communities in which they live," as these are influenced "by the practices adopted by the society as a whole" (Townsend 1954:134).

Townsend (1979:31) defines relative poverty as follows: "Individuals, families, and groups in the population ... lack the resources to obtain the types of diet, participate in the activities, and have the living conditions and amenities which are customary, or are at least widely encouraged and approved, in the societies to which they belong." When people's command of resources slips so low, Townsend (1979:31) maintains, "they are, in effect, 


\section{Defining poverty as distinctively human}

excluded from ordinary living patterns, customs and activities". A relative definition of poverty judges that people are poor if they do not have sufficient resources to participate in the style of life of the communities of which they form part (see Townsend 1979:54-88). If people do not have the resources to share, or participate, in the "customs, activities and diets" commonly approved by their society and embodied in its style of living, they are classified as being poor (Townsend 1979:60, 88).

This definition has two attractive features. One is the focus on how poverty, as lack of economic capacities, can have the consequence that poor people cannot participate in the activities of their broader social context. Their poverty thus leads to social exclusion. Another attractive feature is the way that poverty is defined relative to the standard of living within a specific society. Poverty in a hunter-gatherer society must be understood and measured differently from poverty in a modern, industrial democracy. These two attractive features of Townsend's definition also contain two weaknesses. One weakness is Townsend's woolly description of what comprises social participation. Can we define a non-arbitrary list of social activities as part of the society's standard of human living that people ought to participate in? Townsend uses words like "types of custom and social activity," "diets," and "home, environmental and work conditions" to closer delineate what styles of living involve. These words depict a rather comprehensive set of human activities that most people only partially engage in. Is it possible to narrow down the general abstract requirement of social participation?

Although a lot of important research has been done on poverty since Townsend formulated his views on relative poverty, no one has convincingly addressed the issues raised above. The milestone event of 117 heads of state or government who met in Copenhagen in March 1995, made "the conquest of poverty, the goal of full employment and the fostering of stable, safe and just societies their overriding objectives," did not produce a much better definition of relative poverty. In addition to their definition of absolute poverty discussed above, the Copenhagen Declaration's definition of overall poverty is articulated by Gordon (2000:52) as "not having those things that society thinks are basic necessities and, in addition, not being able to do the things that most people take for granted". This definition is hardly anymore detailed or specific than Townsend's version. The same goes for the Council of Europe's definitions of 1975, as modified by the European Community in 1984: poor people are those individuals or families "whose resources (material, cultural, or social) are so small as to exclude them from a minimum acceptable way of life in the member state in which they live" (quoted by Gordon 2002:58). 
A second weakness of Townsend's definition is the correct, but incomplete emphasis on the relative nature of this kind of poverty. Can this kind of poverty that causes social exclusion only be defined in terms of the social conditions of the society to which the individual belongs? Is Halleröd (2000:167) correct that what is "deemed as 'severe deprivation' will always depend on the ordinary lifestyle and way of consumption that prevails in a society"? Is it not possible to embody a universal element in this definition, to formulate a set of generic social activities that humans throughout the ages have engaged in? Will it then be possible to judge a society's level of poverty or riches by determining the spectrum of such activities available and by measuring the extent to which its members are enabled to participate? Imagine a society where a lack of economic capacities is responsible for the particularly narrow spectrum of such activities the society offers and for the low level of participation of members in those limited activities. Surely this society would qualify as poor in terms of a universal standard applicable to all human societies?

One of the few philosophers who seriously thought about poverty comes a lot closer to reconciling a more universal definition of poverty with Townsend's definition of relative poverty. John D Jones acknowledges that styles of living are determined by a specific society "within the determinate historical situation in which they live" (Jones 1990:67). The crucial move that Jones makes is to link this idea of "a mode of life customary in their society" with the idea that such a life is one judged by a particular society to be "minimally fit and appropriate for people and thus minimally required for an appropriate realization of human dignity" (Jones 1990:67). This move by Jones gives us access to the possibility of a universal definition of poverty applicable to all human societies. Poverty could thus be defined a lack of sufficient economic capacities to engage in a set of basic, fundamental human social activities that defines what it means to live as a human being in a particular place and time (see also John Veit Wilson, in Gordon \& Townsend 2000:158). This definition makes sense of the experience reported by World Bank researchers who were struck by both the universality and the specificity of people's experiences with poverty all over the world, "As we moved more deeply into analyses of poor people's experiences with poverty, we were struck repeatedly by the paradox of the location and social group specificity of poverty, and yet the commonality of the human experience of poverty across countries" (Narayan et al 2000:3).

The possibility now exists for defining a broad, universal set of social activities that any particular human community practices in their own culturally unique way. I want to claim that most human communities known throughout 


\section{Defining poverty as distinctively human}

history would have engaged in the following set of activities in their own culturally defined way, if they had sufficient economic capacities to do so. The principal activities in human communities are those that secure adequate food, clothing, shelter, security and medical care to ensure the survival of the group. Most other social activities focus on fostering social co-operation and enhancing social solidarity, crucial for survival and prerequisites for achievement of a rich and diverse cultural life. Typical activities include governance of diverse aspects of the community's shared life to maintain social order, education to train and equip others to fulfil useful tasks, initiation ceremonies for welcoming new participants in diverse social practices, thanksgiving events for expressing gratitude for services rendered in smaller or larger contexts, celebration of significant events on smaller (family) and larger (society) scale, and entertainment to amuse and amaze others through expressing rare individual and team talents and skills.

The rationale for this set of human activities is that they seem to encapsulate the set of activities human communities have engaged in throughout known history. Engaging in a configuration of such activities expresses our humanity. Put differently, to qualify as human, communities should be economically able to enact their versions of such activities. Any normally functioning human community ought to have the economic capacities to generate and sustain their own interpretation and expression of such activities practiced by all human beings throughout history in their own distinctive ways. If this is true, we have a universal, albeit an approximate, standard to determine the level of poverty or riches of a particular society.

Let us explore this idea. Society $X$ has been poor for many decades and in addition has suffered severe droughts over the past few years. Agriculture is the main source of income. Although they share their minimal resources with one another, many have died as a result of not having enough food to eat. Virtually all of them are living in absolute poverty. They do not have resources to feed themselves properly, let alone any reserves they can use for celebrating birthdays, religious festivals, or public holidays. Although they can still entertain one another through telling stories, they had to close their radio station and cannot afford any theatre productions. Many of them are so bogged down by the problems of their society and have so little energy as a result of their diets low in nutritious foods that they do not participate in such entertainment activities anymore. On visiting such a community, people from non-poor countries would typically exclaim: "This is not the way humans should live!"

Society $X$ is similar to many known societies throughout the world. Such societies are poor as a whole, because they do not have the economic 
capacities to set up, run, and maintain the most basic social activities one expects to find in any human society.

\section{CONCLUSION}

In this essay I have developed the following ideas.

- Poverty is a concept uniquely applied to humans to indicate when a specific person has fallen below the standard of life thought appropriate for someone in that culture.

- Absolute poverty means that a person does not have adequate economic capacities to provide adequate food, clothing, shelter, security, and medical care to maintain their physical health.

- Relative poverty means that although people have adequate economic capacities to provide adequate food, clothing, shelter, security, and medical care to maintain their physical health, they cannot participate in any other activities regarded as indicative of being human in that society.

To be poor thus means to suffer as a result of all the consequences of not having enough economic capacities. Poor people experience the humiliation of not being able to live fully human lives as specified by their society. Poverty entails the desolation of realizing that others do not care that you experience poverty in all its fullness, while they furthermore deny any responsibility in the genesis of your situation, as well as shirk their responsibility for improving your lot. Many morally sensitive people experience moral outrage that humans are allowed to suffer such deplorable conditions. Others are reluctant to acknowledge the full impact of poverty on fellow human beings and they avoid the discomfort and challenge of recognising the inhumane situation of poor people.

\section{Works consulted}

Alcock, P 1993. Understanding poverty. Houndmills: MacMillan.

Booth, C 1892. Pauperism: A picture and endowment of old age. London: MacMillan. Dasgupta, P 1992. An inquiry into well-being and destitution. Oxford: Clarendon.

Gordon, D, Pantazis, C \& Townsend, P 2000. Absolute and overall poverty: A

European history and proposal for measurement, in Gordon, D \& Townsend, P (eds), Breadline Europe: The measurement of poverty, 79-105. Bristol: Policy Press. 


\section{Defining poverty as distinctively human}

Gordon, D 2000. Measuring absolute and overall poverty, in Gordon, D \& Townsend, $\mathrm{P}$ (eds), Breadline Europe: The measurement of poverty, 49-77. Bristol: Policy Press.

Gordon, D 2002. The international measurement of poverty and anti-poverty policies, in Townsend, P \& Gordon, D (eds), World poverty: New policies to defeat and old enemy, 53-80. Bristol: Policy Press.

Halleröd, B 2000. Poverty, inequality and health, in Gordon, D \& Townsend, P (eds), Breadline Europe: The measurement of poverty, 165-187. Bristol: Policy Press.

Jones, J D 1990. Poverty and the human condition: A philosophical inquiry. Leviston: Edwin Mellen.

Narayan, D (with Patel, R, Schafft, K, Rademacher, A, Koch-Schulte, K) 2000. Voices of the poor: Can anyone hear us? New York: Oxford University Press for the World Bank.

Roll, J 1992. Understanding poverty: A guide to the concept and measures. London: Family Policy Studies Centre.

Rowntree, B Seebohm. 1901. Poverty: A study in town life. London: MacMillan.

Sen, A 1984. Well-being, agency and freedom: The Dewey Lectures 1984. The Journal of Philosophy 4, 169-220.

Squire, L 1993. Fighting poverty. The American Economic Review 83(2), 377-382.

Srinivasan, T N 1994. Human development: A new paradigm or a reinvention of the wheel?" The American Economic Review 84(2), 238-243.

Streeter, P 1994. Human development: Means and ends, The American Economic Review 4(2), 232-237.

Tarp, F, Simmler, K, Matusse, C, Helberg, R, Dava, G 2002. The robustness of poverty profiles reconsidered, Economic Development and Cultural Change 51(1), 77-108.

Temkins, L 1993. Inequality. New York: Oxford University Press.

The Copenhagen Declaration and Programme of Action 1995. World Summit for Social Development, 6-12 March 1995. New York: United Nations Department of Public Information.

Townsend, P 1954. Measuring poverty. The British Journal of Sociology 5(2), 130137.

Townsend, P 1979. Poverty in the United Kingdom: A survey of household resources and standards of living. London: Allen Lane. (Penguin Books.)

UNDP (United Nations Development Programme.) 1997. Human Development Report. New York: Oxford University Press.

UNDP (United Nations Development Programme.) 2000. Overcoming human poverty. New York: UNDP.

Wilson, J V 2000. Horses for discourses: Poverty, purpose and closure in minimum income standards policy, in Gordon, D \& Townsend, P (eds), Breadline Europe: The measurement of poverty, 141-164. Bristol: Policy Press.

World Bank. 1990. World Development Report 1990. New York: Oxford University Press. 